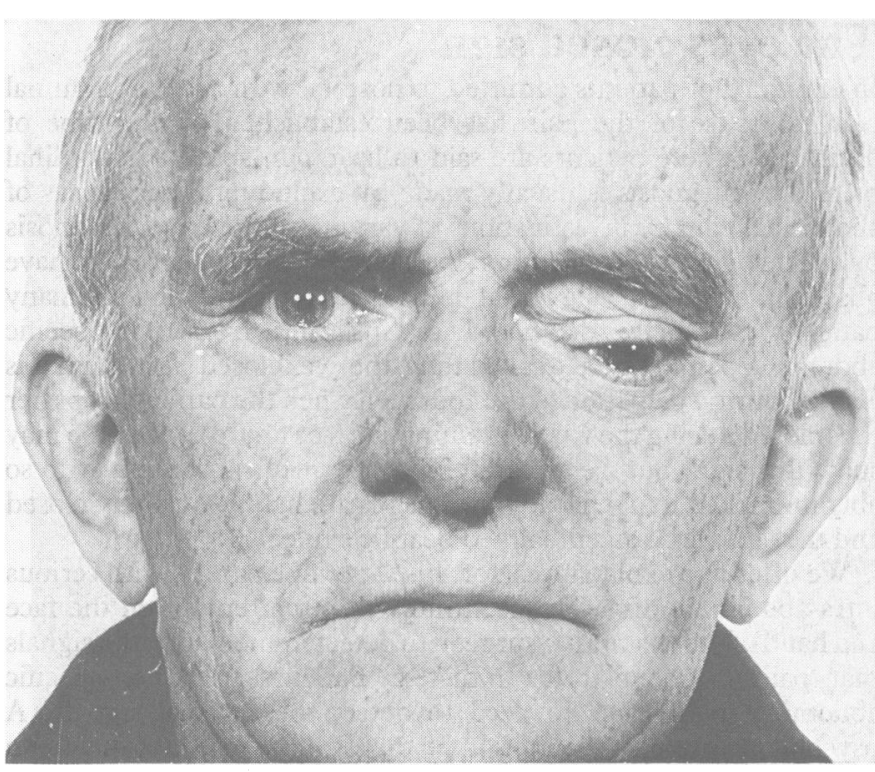

\section{Paget's disease of the orbit: before and after APD}

A 62 year old man with Paget's disease of bone presented with double vision and severe proptosis, with downward and outward displacement of his left eye, and cranial enlargement. Five years later his head was larger and his eyeball further displaced (figure above). The left eye was immobile, and two years previously his optician had found visual acuity to be $6 / 12$ on the left and $6 / 6$ on the right. His serum alkaline phosphatase activity was 2745 IU/1 (normal range 30-130) and the urine hydroxyproline:creatinine ratio was 0.308 (normal range $0.003-0.015$ ). Calcitonin injections produced no improvement, and the patient was then treated with 12 weekly infusions of $30 \mathrm{mg}$ 3-aminohydroxypropylidene-1,1bisphosphonate (APD) in $250 \mathrm{ml}$ of saline, followed nine months later by a further course of six weekly infusions of $30 \mathrm{mg}$ APD. His facial appearance and vision improved dramatically and unexpectedly (figure below), and serum alkaline phosphatase activity fell to $305 \mathrm{IU} / \mathrm{l}$ and urine hydroxyproline: creatinine ratio 0.045 . His optician found that his squint had resolved and he had 6/5 vision in both eyes. - H M BUCKLER, J A CANTRILL, P S KLIMIUK, D C ANDERSON, University Departments of Medicine, Pharmacy, and Rheumatology, Hope Hospital, Salford M6 8HD.

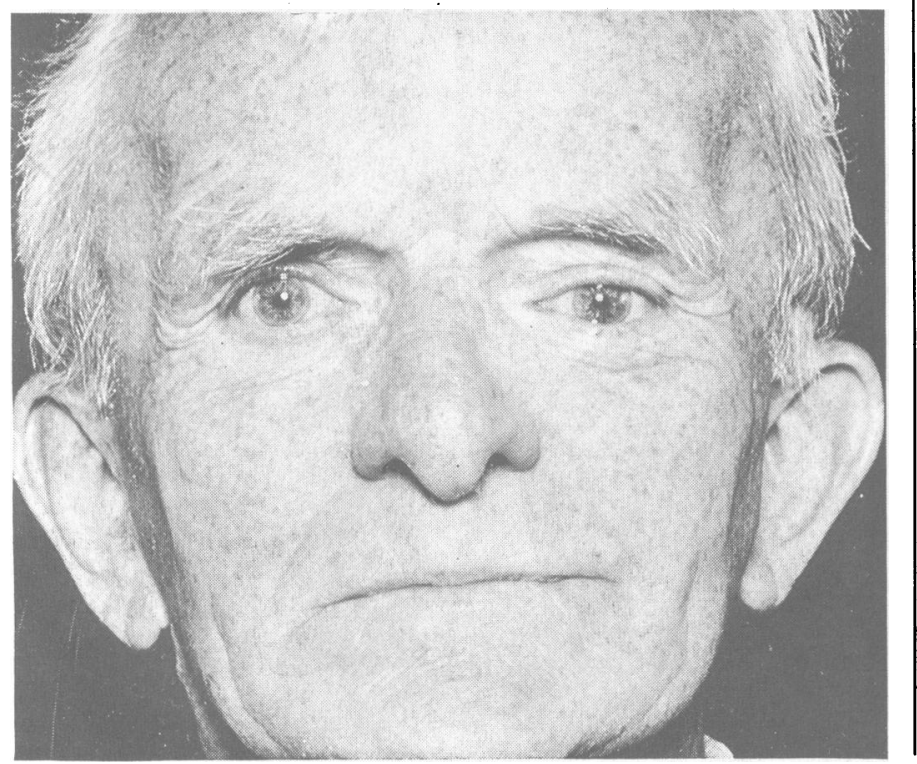

\section{Misdiagnosis of the Chilaiditi syndrome}

A 68 year old man was admitted as an emergency with generalised abdominal pain of recent onset. His abdomen was tense with generalised guarding, and he had no bowel sounds. A chest radiograph taken with the patient erect(figure top) was interpreted as showing gross pneumoperitoneum, and we diagnosed perforation of an intra-abdominal viscus. Laparotomy was advised, but the patient refused and so was treated conservatively. He improved. A gastrografin meal was normal, but a gastrografin enema showed that what we had thought was a pneumoperitoneum was in fact a dilated colon interposed between the liver and the diaphragm (Chilaiditi syndrome) (figure bottom). This usually asymptomatic syndrome was first described by Beclere in 1899, but since Chilaiditi described three patients in 1910 it has been known as Chilaiditi syndrome. ${ }^{1}$ It has a general incidence in the population of between $0.02 \%$ and $0.22 \%$. C C R BISHOP, S M WHITEHEAD, B T JACKSON, St Thomas's Hospital, London SE1 7EH.

1 Chilaiditi D. Zur Frage der Hepatoptose und Ptose in allgemeinen in Anschluss an drei Falle von temporarer, partieller Leberverlagerung. Fortschritue ouf dem Gebiete der Rontgenstrahlen 1910-11;16:173-208
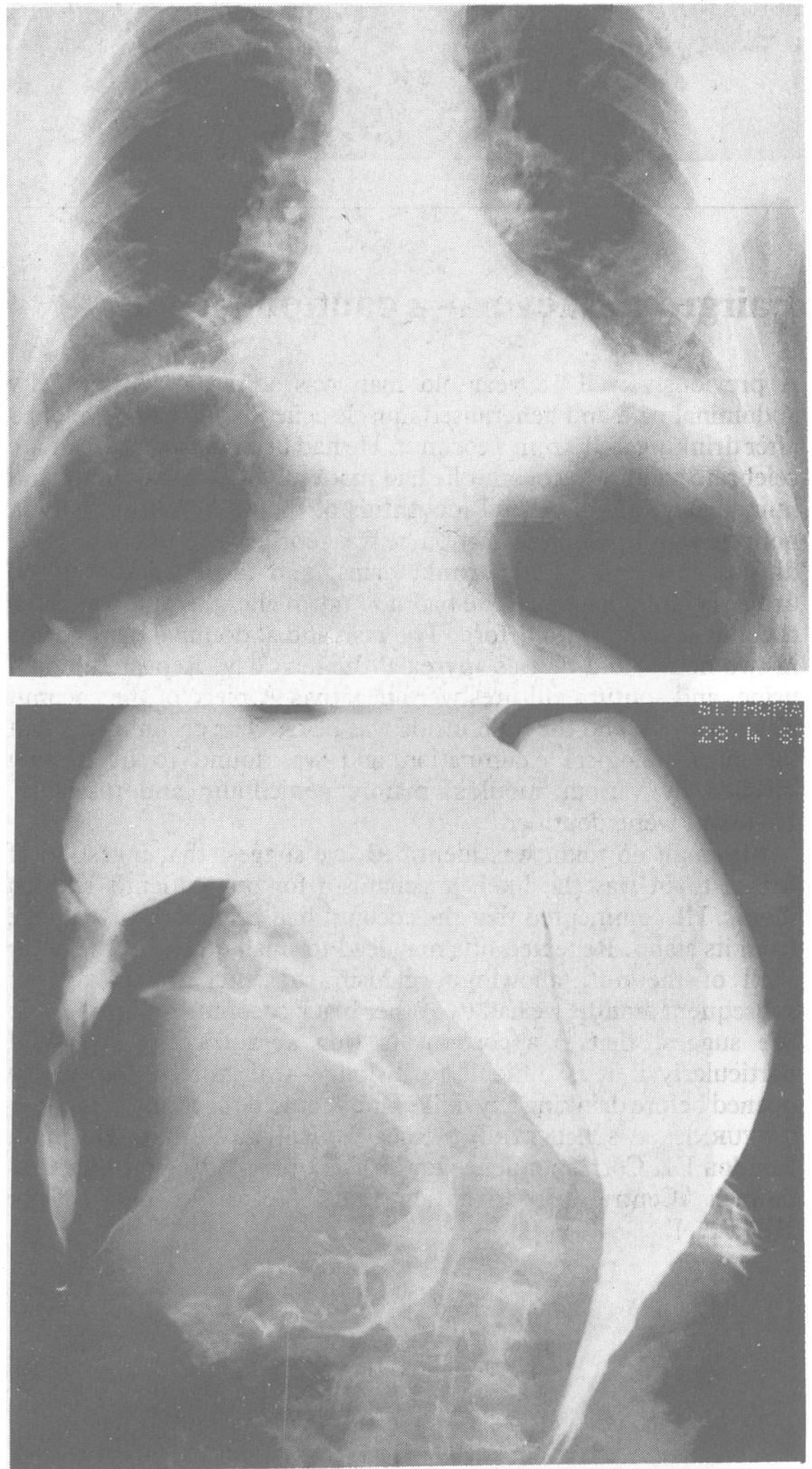